\title{
Abordagem de Gêneros Discursivos Orais em Liuros Didáticos de Língua Espanhola
}

\section{Oral Discursive Genre Approach in Spanish Language Textbooks}

\section{Margarida Rosa Álvares* Elena Ortiz Preuss**}

Resumo: Estudos diversos apontam que o trabalho com os gêneros orais tem sido marginalizado em sala de aula. Porém, muitas vezes, as dificuldades na comunicação oral surgem em virtude do desconhecimento sobre o gênero discursivo, embora o falante tenha conhecimento sobre o sistema linguístico. A partir dessa constatação e considerando o papel dos livros didáticos (LDs) no processo de ensino-aprendizagem, de línguas, neste artigo pretendemos analisar como são abordados os gêneros orais em duas coleções didáticas de língua espanhola. Para isso, realizamos uma pesquisa bibliográfica, na qual analisamos coleções escolhidas pelo Programa Nacional do Livro Didático (PNLD), nos anos de 2012 e 2015. Para cumprir com nosso objetivo, expusemos um panorama teórico sobre os gêneros discursivos e discursivos orais, apresentamos a metodologia adotada e as análises realizadas, as quais possibilitaram observar que ainda há, nessas coleções, uma primazia pelo trabalho pedagógico a partir de gêneros escritos, embora na comparação entre as obras, a coleção mais recente apresenta mais atividades com gêneros discursivos orais.

Palavras-chave: Gêneros orais. Espanhol. Livros didáticos.

\footnotetext{
* Mestre em Letras e Linguística pela Universidade Federal de Goiás - UFG (2007). Professora Assistente 2 - UFG. Contato: margaridaalvares@yahoo.com.br.

** Doutora em Estudos da Linguagem, Especialidade em Linguística Aplicada, pela Universidade Federal do Rio Grande do Sul - UFRGS (2011). Professora Doutora Adjunto II - UFG. Contato: elena.ortizp@yahoo.com.br.
} 
Abstract: Several studies point that the oral genres have been marginalized in the classroom. However, often, difficulties in oral communication arise because a lack of knowledge about the discursive genre, although the speaker has the knowledge about the linguistic system. From this evidence and considering the role of textbooks in the language teaching learning process, in this article we aim to analyze how oral genres are treated on two textbooks of Spanish language. For this, we carry out a bibliographic research in which we analyzed textbooks chosen by the Programa Nacional do Livro Didático (PNLD), in the years of 2012 and 2015. To achieve our goal, we exposed a theoretical overview about discursive genres and oral discursive genres, present the methodology adopted and the performed analyzes, which made it possible to note that in the collections there are still primacy by the pedagogical work from written genres, although when comparing the approach, the latest textbook presents more activities with oral discursive genres.

Keywords: Oral genre. Spanish language. Textbooks.

\section{Introdução}

O trabalho com os gêneros discursivos pressupõe o entendimento da língua como interação e uma mudança na visão de como aprender e ensinar línguas. A abordagem pedagógica baseada em gêneros discursivos desconsidera como único eixo norteador as regras prontas e acabadas e concebe o processo de produção dos gêneros e a relação construída destes com as atividades humanas dentro de um determinado contexto. O gênero, segundo Bakhtin (2003), faz parte do processo de interação entre os seres humanos e só se materializa através dessa perspectiva.

Os gêneros discursivos, orais ou escritos, na prática, apesar de estarem presentes nos documentos oficiais que norteiam o ensino de línguas, ainda parecem ser pouco ou superficialmente utilizados em sala de aula (AQUINO, 2011). Muitas vezes, diferentemente do proposto por Bakhtin (2003), os gêneros são abordados a partir de uma perspectiva estruturalista, sendo rotulados e ensinados como fórmulas prontas e acabadas, ignorando-se que 
as formas de gênero são "bem mais flexíveis, plásticas e livres que as formas da língua” (BAKHTIN, 2003, p. 283).

No caso da oralidade - a qual, segundo Marchuschi (1997), desempenha papel central nas relações interpessoais em nossa sociedade -, observa-se que, no ambiente escolar, tem um status secundário, no sentido de que há pouca ênfase no trabalho pedagógico em prol do desenvolvimento da habilidade oral. Dolz, Noverraz e Schneuwly (2004), por sua vez, salientam que não se pode partir do pressuposto de que os alunos dominem todas as manifestações dos gêneros orais e orientam que, na sala de aula, deveriam ser explorados gêneros que o aluno não domine satisfatoriamente, para que ele possa interagir em diversas situações de comunicação. Além disso, considerando que, muitas vezes, os falantes sentem dificuldades para poderem se expressar por não dominar certos gêneros, seja em sua língua materna (doravante LM), seja em sua língua estrangeira (doravante LE), e que os livros didáticos (doravante LDs) têm um papel significativo nos processos de ensino-aprendizagem de línguas, entendemos que os LDs podem ajudar a ampliar o conhecimento sobre gêneros usados em diferentes contextos de comunicação.

Assim, levando em consideração a importância do desenvolvimento da oralidade em LE e do papel do LD nos processos de ensinoaprendizagem de línguas, apresentamos neste artigo um estudo que tem como objetivo, analisar a abordagem de gêneros discursivos orais em LDs de língua espanhola, observando até que ponto ela contempla a perspectiva bakhtiniana de gênero e a essência da habilidade oral. Para isso, analisamos duas coleções que foram indicadas pelo Programa Nacional do Livro Didático (PNLD), o qual valoriza o trabalho com gêneros discursivos. O artigo inicia com uma breve exposição teórica sobre gêneros, verticalizando a discussão sobre os gêneros orais. A partir disso, descrevemos os procedimentos metodológicos adotados e, em seguida, apresentamos as análises dos LDs. Posteriormente, expomos as considerações finais e as referências.

\section{Gêneros Discursivos}

O gênero discursivo pode ser entendido como forma de comunicação decorrente de uma prática social e um "tipo relativamente estável de 
enunciado" (BAKHTIN, 2003, p. 262) e é composto por conteúdo temático, estilo e construção composicional. Bakhtin (2003) ressaltou que esses elementos estão intrinsecamente relacionados e propiciam aos gêneros do discurso uma infinidade de possibilidades de manifestação.

O conteúdo temático, ao qual se referiu Bakhtin (2003), está relacionado ao tema geral do gênero, ao contexto em que ele está inserido; o estilo se refere aos "estilos de gênero de determinadas esferas da atividade humana e da comunicação” (BAKHTIN, 2003, p. 266), ou seja, a partir das possibilidades estilísticas que a língua oferece, o falante faz sua escolha para que torne sua fala mais ou menos formal, ou que simplesmente não obedece a nenhuma regra criando, um estilo mais livre. Assim, determinados estilos pertencem a determinados gêneros. Já a construção composicional está relacionada ao modo de organização e à construção do texto. Rosa (2010, p. 4) considera que "Quando um gênero é produzido dentro de uma determinada esfera de comunicação humana, sua principal intenção é estabelecer uma ação de linguagem específica, que produza sentido e estabeleça a comunicação pretendida", e, para que essa comunicação pretendida ocorra de maneira satisfatória, é necessário que os elementos componentes dos gêneros discursivos estejam relacionados e sejam todos considerados.

Bezerra e Reinaldo (2013), ao diferenciarem os gêneros textuais dos gêneros discursivos, pontuam que os gêneros textuais estão colocados dentro de uma perspectiva formalista, vendo a gramática do texto como ponto mais relevante. Para esses autores, as teorias que consideram os gêneros discursivos os veem como uma "ação social, focalizando mais os contextos e os processos relacionados a seu uso" (BEZERRA; REINALDO, 2013, p. 65) e, nesse cenário, o elemento linguístico ocupa lugares distintos, ganhando ou perdendo destaque a partir da necessidade do contexto. Diferenciar esse entendimento teórico do que vem a ser um gênero discursivo e um gênero textual faz-se necessário porque a sua concepção implica em diferentes análises, sejam elas linguísticas ou não. Em poucas palavras, o gênero discursivo abrange um todo ideológico, de caráter bem bakhtiniano, que pode ser desconsiderado ao se fazer uma análise levando em consideração a concepção de gênero textual, pois pode se ater, especificamente, à apreciação de elementos linguísticos presentes no texto. Não pretendemos reduzir o gênero 
discursivo a uma definição simplista, tampouco desmerecer os estudos acerca dos gêneros textuais. Nossa intenção é somente apresentar, de forma sucinta, seus elementos constituintes e ressaltar seu caráter ideológico. Como bem expõem Brait e Pistori (2012), ao discorrer sobre os vários conceitos de gênero, não apenas na Estética da Criação Verbal de Bakhtin (2003), mas percorrendo todo o Círculo, o gênero é

... o conjunto dos modos de orientação coletiva dentro da realidade, encaminhando para a conclusão de que, por meio do gênero, é possível compreender novos aspectos da realidade, ou, em outras palavras, a realidade do gênero é a realidade social de sua realização no processo de comunicação, ligadas de forma estreita ao pensar. (BRAIT; PISTORI, 2012, p. 385).

Assim, compreendemos o gênero como uma construção coletiva, mutável, adaptável e múltipla, que depende de um contexto social e ideológico para existir, manifestar-se e poder circular na sociedade; o gênero como interação. Ou, ainda, com as palavras de Lopes-Rossi (2012, p. 230),

As propriedades típicas de qualquer produção de linguagem (gênero discursivo) só podem ser descritas se considerados: o contexto sócio-histórico, que, de modo geral, determina todas as propriedades sociocomunicativas do gênero - condições de produção, de circulação e recepção, propósito comunicativo, temáticas possíveis -; os elementos composicionais verbais e não verbais e, ainda, o estilo.

\section{Gêneros discursivos orais}

Uma das materializações dos gêneros discursivos é a oralidade. Mesmo nas sociedades em que os gêneros escritos regem as normas na sociedade, o gênero oral está presente e se manifesta em muitos contextos, em alguns até se sobrepondo ao uso da palavra escrita. Swiderski e Costa-Hübes (2011) consideram que ao longo do nosso desenvolvimento nos é exigido o uso social dos gêneros orais em escalas mais ou menos formais. 
Considerando-se que os gêneros orais mais praticados na sociedade são a conversa espontânea ou familiar, os gêneros discursivos orais secundários precisam estar presentes no espaço escolar. Dolz, Schneuwly e Haller (2004) defendem que a oralidade deve fazer parte das práticas em sala de aula e que os gêneros orais de caráter público formal têm de ser trabalhados, pois os alunos terão menos contato com esse tipo de produção, mas é importante que estejam preparados para lidar com manifestações orais dessa natureza.

Alguns gêneros orais existem sem o apoio nos gêneros escritos, ou seja, alguns guardam características marcadamente orais, outros se apoiam nos gêneros escritos para existirem ou simplesmente para se manifestarem de outra forma. Lopes-Rossi (2012) lista alguns exemplos de gêneros discursivos que se realizam em distintas situações de interação:

Uma conversa, uma piada, um provérbio, uma entrevista, uma palestra, uma explicação, uma apresentação oral de um trabalho, um interrogatório, um depoimento, um cordel, são alguns exemplos de gêneros orais. Carta, requerimento, procuração, notícia, reportagem, propaganda, bilhete, romance, conto, poema, charge, relatório, receita, lista de compra, cartão de felicitação, nota fiscal, recibo, verbete de dicionário, cheque, são exemplos de gêneros escritos. (LOPES-ROSSI, 2012, p. 227).

No caso da exposição oral, do teatro ou da leitura para outras pessoas percebemos uma aproximação ou dependência mais estreita com a escrita, mas, no caso do debate ou da conversa, o distanciamento da escrita é mais evidente, como ressaltam Rojo e Schnewly (2006). Ainda sob essa perspectiva e conforme Vázquez (2000), a língua falada tem duas funções: a transacional e a interacional. A primeira função diz respeito ao objetivo de transmitir informação (como no caso da exposição oral) e a segunda se refere à manutenção das relações sociais (como a conversa). Assim, a oralidade assume características específicas que comumente são desconsideradas nos LDs, como a sua interdependência contextual (o sentido aportado pelos gestos, tons de voz, a estrutura de tomada de turnos, os princípios de cooperação conversacional e o grau de relação entre os interlocutores). Essa concepção 
é consoante com os pressupostos da Análise da Conversação (AC) atualmente também conhecida como Análise da fala-em-interação - que trata de descrever e analisar os fenômenos da oralidade, problematizando, entre outros elementos, a estrutura da tomada de turnos, de reparo e pares adjacentes (SILVA; ANDRADE; OSTERMANN, 2009).

Além disso, para Cestero Mancera (2000), a comunicação requer o conhecimento de signos culturais (hábitos de comportamento, crenças, etc.) e sistemas (não) verbais. A autora argumenta que a comunicação não verbal se refere ao conjunto de sistemas "paralingüístico, cinésico, proxêmico e cronêmico". Portanto, os gêneros orais envolvem também o domínio de elementos não linguísticos, tais como: a expressão facial, o posicionamento espacial, a consideração acerca da distância espacial, o tom de voz, o ritmo, a adequação às tomadas de turno, a entonação, etc., e esses elementos devem ser considerados ao se propor um trabalho com os gêneros orais. Para que seja uma prática interacional efetivada com êxito, é necessário que sejam bem manejados os elementos verbais e não verbais. Nos exemplos apresentados por Lopes-Rossi (2012), é possível perceber que os elementos não linguísticos diferem de um gênero para o outro, principalmente se considerarmos as diferentes produções de linguagem e os participantes envolvidos na interação.

Os elementos citados anteriormente variam de acordo com o gênero exigido em determinada prática social. Normalmente, os alunos têm facilidade em lidar com os gêneros mais elementares, repetidos nas práticas familiares e cotidianas. Quando lhes é solicitado que opinem, argumentem, entrevistem, etc., a tendência é que as dificuldades apareçam, assim, faz-se necessário que as características pertencentes a determinados gêneros, considerando seus aspectos linguísticos e não linguísticos, sejam explicitadas no processo de ensino e aprendizagem. Além dos elementos citados, é de suma relevância que os interlocutores envolvidos no processo de interação e as condições contextuais, sócio-históricas e ideológicas sejam consideradas para a observação e o ensino da oralidade na sala de aula. 


\section{Metodologia}

A partir de um estudo bibliográfico, analisamos duas coleções de língua espanhola que foram selecionadas pelo Programa Nacional do Livro Didático (PNLD), nos anos de 2012 e 2015 . A coleção intitulada Síntesis - Curso de lengua española, de Ivan Martin, Editora Ática, foi uma das três selecionadas pelo PNLD de 2012 para ser distribuída nas escolas públicas do Brasil. A versão analisada e selecionada pelo PNLD estava dividida em três volumes, considerando as três séries do Ensino Médio. Neste estudo, analisamos o volume único, anterior à coleção dividida, mas que guarda praticamente as mesmas características da versão atualizada.

A segunda coleção analisada se intitula Cercanía Joven: espanhol: ensino médio, de Ludmila Coimbra, Luiza Santana Chaves e Pedro Luis Barcia. O material, publicado pela Edições SM, foi um dos selecionados pelo PNLD de 2015. Também nesse caso, o PNLD selecionou a versão subdividida em três volumes, mas nosso estudo vai analisar o volume único, considerando que não houve mudanças significativas no conteúdo da coleção.

Nossa análise teve início com a seleção dos livros a serem analisados. Consideramos que seria relevante analisar obras selecionadas pelo PNLD, tendo em vista o alcance que o programa tem ao distribuir livros nas escolas públicas de todo o país. Com essa iniciativa, muitos alunos e professores passam a ter acesso a materiais que talvez não pudessem conhecer se não houvesse esse programa. A opção pela coleção do PNLD $2012^{2}$ (Sintesis: Curso de lengua española) é devido ao fato de que, conforme o Guia de Livros Didáticos: PNLD 2012: Lingua Estrangeira Moderna (BRASIL, 2011, p. 11), essa obra foi considerada a que melhor atendia aos critérios de avaliação nos

\footnotetext{
${ }^{1}$ Nosso propósito não é discutir o PNLD. Somente optamos por analisar duas obras indicadas, pois esse programa atende às normativas educacionais vigentes, as quais valorizam o trabalho com gêneros. Trata-se, portanto, de se ter um critério mais objetivo para selecionar as obras a serem analisadas. Tanto é assim que não nos preocupamos em analisar todas as que foram selecionadas. Além disso, por razões logísticas, nossa análise foi feita em edições de volume único, não as fracionadas, que foram as indicadas pelo programa.

2 As coleções selecionadas no PNLD 2012 foram: El arte de leer en español; Enlaces: español para jóvenes brasileños e Sintesis: Curso de lengua española.
} 
itens envolvendo o trabalho com a oralidade (compreensão ${ }^{3}$ e produção oral ${ }^{4}$ ). Por outro lado, a opção pela coleção do PNLD 2015 (Cercanía Joven: espanhol: ensino médio), foi aleatória, uma vez que ambas as coleções selecionadas ${ }^{5}$ nessa edição do PNLD, têm uma preocupação explícita pelo trabalho a partir de gêneros orais e escritos, mas fizemos uma análise qualitativa da abordagem feita em cada uma das obras.

Após a seleção das obras, passamos à etapa de análise, considerando a concepção de gêneros discursivos orais, a natureza da habilidade oral e os seguintes questionamentos:

- Como a oralidade é abordada na coleção?

- Em quais partes aparecem atividades que contemplam a prática oral?

- Os gêneros orais são considerados nas práticas orais propostas?

- Se os gêneros orais aparecem, como eles são trabalhados?

- Há variedade dos gêneros abordados?

${ }^{3}$ Os critérios de avaliação na compreensão oral no PNLD 2012 eram: "68. Os textos orais são autênticos e de diferentes gêneros e tipos textuais, com propósitos variados? (Obs.: Considerar conteúdo do CD de áudio.). 69. Os textos orais apresentam amostra de diversas variedades linguísticas (sociais e regionais)? (Obs.: Considerar conteúdo do CD de áudio.). 70. O trabalho com a compreensão oral envolve compreensão intensiva (entendimento de sons, palavras e sentenças), extensiva (compreensão global) e seletiva (identificação de informação específica)? 71. O trabalho com a compreensão oral promove a interpretação do texto em relação a seus objetivos, condições de produção e as prováveis reações dos interlocutores? 72 . CD de áudio apresenta boa qualidade de som e existem, no livro do aluno e no manual do professor, indicações precisas que facilitem a localização das faixas?”' (BRASIL, 2011, p. 17).

${ }^{4}$ Os critérios de avaliação na produção oral no PNLD 2012 eram: “73. Existem oportunidades para o aluno usar diferentes estratégias de comunicação (verbais e não verbais)? 74. Existem possibilidades para o aluno se comunicar em situações diversas (conversação, entrevistas, debates, apresentação de trabalhos, dramatizações, leitura, inclusive de textos poéticos e outros gêneros orais)? 75. As atividades de produção oral permitem o uso de diversas funções comunicativas? 76. Existem oportunidades para o aluno discutir e escolher os registros, as variedades de linguagem e os itens lexicais adequados a cada situação comunicativa?” (BRASIL, 2011, p. 18).

${ }^{5}$ As coleções selecionadas no PNLD 2015 foram Cercanía Joven: espanhol: ensino médio e Enlaces: español para jóvenes brasileños. 
Ressalte-se que, no tocante à compreensão oral no PNLD, os avaliadores devem observar, na coleção, se há materiais registrados em áudio e baseados em gêneros e se as práticas orais permitem que os jovens interajam na LE. Há, ainda, a preocupação com o uso de distintos registros da língua.

A seguir, passaremos a expor as análises, primeiro da coleção Sintesis: Curso de lengua española e, depois, da coleção Cercanía Joven: espanhol: ensino médio.

\section{Estrutura e Apresentação do Livro Didático Síntesis: curso de lengua española}

O volume único selecionado para análise é composto por 416 páginas, incluindo o Manual do professor, com 24 páginas. Está subdividido em três unidades, que correspondem aos exemplares separados na veiculação atualizada. Cada unidade possui oito capítulos temáticos e segue uma sequência padronizada, que se repete em todos os capítulos do livro.

Cada capítulo é aberto com uma seção intitulada Para oír y comprender que contém um áudio e uma sequência de quatro atividades de compreensão: a primeira se refere à compreensão geral sobre o que é dito no áudio, sem que o aluno leia o texto. A segunda atividade solicita outra audição, acompanhada da leitura do texto. A terceira atividade traz perguntas de compreensão acerca do texto, e a quarta (intitulada Ahora habla de ti ${ }^{7}$ ) propõe perguntas de acordo com a temática do texto para serem respondidas pelo aluno, considerando sua vivência.

A continuação do capítulo contém, ainda, as seguintes seções:

- Algo de vocabulario - com questões relacionadas ao vocabulário específico da temática abordada;

- Gramática básica - com questões de gramática normativa;

- Para leer y reaccionar - com um texto principal e questões de compreensão;

${ }^{6}$ Para ouvir e compreender. Todas as traduções ao longo do texto serão colocadas em nota de rodapé e são de nossa responsabilidade.

${ }^{7}$ Agora fale de você. 
- Aprende un poco más - esta é uma das seções que apresenta mais diversidade ao longo dos capítulos. Traz questões de: áudio, vocabulário, compreensão textual, questões de tradução, etc.;

- Para charlar y escribir - seção com propostas de expressão oral e de expressão escrita.

- Para leer y reflexionar ${ }^{8}$ - com um texto complementar e questões de compreensão.

Após a apresentação da organização do LD, nos deteremos em parte da seção Para oír y comprender e da seção Para charlar y escribir, para a análise sobre a abordagem dos gêneros discursivos orais.

$\mathrm{Na}$ apresentação do livro, o autor afirma que o material foi elaborado para jovens e adultos do ensino médio ou superior. Ressalta que aprender um idioma vai além de conhecimentos gramaticais ou de estruturas comunicativas, e que é necessário estar disposto a entrar em contato com outras culturas. No Manual do professor (MARTIN, 2009, p. 2), o autor afirma que a coleção "está afinada com os Parâmetros Curriculares Nacionais e com as Orientações Curriculares para o ensino de espanhol", portanto, pode-se depreender que segue a perspectiva discursiva de trabalho com os gêneros. Além disso, podemos observar essa intenção do autor a partir do seguinte fragmento:

Espera-se que o intenso contato do estudante com manifestações discursivas originais em língua espanhola - textos literários, reportagens, anúncios publicitários, cómics, músicas, etc. - possa contribuir efetivamente com a aprendizagem de variedades linguísticas que caracterizam o idioma. (MARTIN, 2009, p. 3).

Nessas palavras, extraídas da apresentação do livro, observamos que a obra tem a preocupação de trabalhar uma diversidade de gêneros no intuito de que variedades linguísticas sejam aprendidas. Essa afirmação está em consonância com a preocupação apresentada no Manual do professor, de que, ao trazer uma diversidade de gêneros, o aluno pode aprender a

\footnotetext{
${ }^{8}$ Um pouco de vocabulário; Gramática básica; Para ler e reagir; Aprenda um pouco mais; Para conversar e escrever; Para ler e refletir.
} 
utilizar o registro adequado às diversas situações e, de certa forma, dialoga com Swiderski e Costa-Hübes (2011) quando falam sobre o uso social dos gêneros.

Com base no que foi exposto e considerando as ressalvas trazidas pelo autor do livro, passamos à análise mais detalhada das seções que trazem o gênero oral de maneira explícita. Vale ressaltar que, em nossa análise, levamos em consideração, também, as orientações dispostas no próprio Guia do PNLD 2012 sobre as questões de compreensão e produção orais e a presença dos gêneros.

Seções específicas do livro didático Síntesis: curso de lengua española

Para responder ao primeiro questionamento trazido em nossa metodologia sobre a abordagem da oralidade na coleção, observamos a disposição das atividades dentro dos capítulos: das sete seções presentes em todos os capítulos, apenas duas oferecem espaço para que o gênero oral seja trabalhado. É importante salientar que consideramos, em nossas análises, também as atividades de compreensão oral, além das de produção.

Na parte de compreensão oral (seção Para oír y comprender), que abre todos os capítulos, embora apresente alguma variedade de gênero, a maioria se refere a diálogos informais. Alguns são somente gravações em áudio de gêneros escritos. Reafirmamos que essas atividades não dão suporte suficiente para uma produção oral satisfatória por parte dos alunos, já que não há, em nenhum momento, uma preparação específica para o gênero oral que será pedido em outro momento (na seção Para charlar y escribir). Cabe ressaltar que, conforme o Manual do professor, na seção Para oír y comprender não se propõe trabalhar gêneros autênticos, mas "são apresentados textos artificiais (geralmente em forma de diálogos, depoimentos e entrevistas) em que figuram as estruturas gramaticais e comunicativas objeto de estudo do capítulo" (MARTIN, 2009, p. 4). Por outro lado, também segundo o Manual, na seção Para charlary escribir são apresentadas estruturas comunicativas a serem utilizadas numa proposta de conversação, a qual servirá de base para a atividade de produção escrita.

O Quadro 1, a seguir, explicitam a variedade de gêneros orais trazidas nas seções analisadas por unidades: 
Quadro 1 - Variedade de gêneros orais presentes na unidade 1

\begin{tabular}{|c|c|c|c|}
\hline Unidade & Capítulo & Seções & Gênero oral ${ }^{9}$ \\
\hline \multirow{16}{*}{1} & \multirow{2}{*}{1} & Para oír y comprender & Diálogo informal ${ }^{10}$ \\
\hline & & Para charlar y escribir & Conversa informal \\
\hline & \multirow{2}{*}{2} & Para oir y comprender & Diálogo informal \\
\hline & & Para charlar y escribir & Entrevista de trabalho \\
\hline & \multirow{2}{*}{3} & Para oir y comprender & Diálogo informal \\
\hline & & Para charlar y escribir & Conversa informal \\
\hline & \multirow[b]{2}{*}{4} & Para oír y comprender & Diálogo informal \\
\hline & & Para charlar y escribir & $\begin{array}{c}\text { Diálogo envolvendo compra e } \\
\text { venda }\end{array}$ \\
\hline & \multirow{2}{*}{5} & Para oír y comprender & Diálogo informal \\
\hline & & Para charlar y escribir & Conversa informal \\
\hline & \multirow{2}{*}{6} & Para oir y comprender & Diálogo informal \\
\hline & & Para charlar y escribir & Jogo de perguntas ${ }^{11}$ \\
\hline & \multirow{2}{*}{7} & Para oíry comprender & Diálogo informal \\
\hline & & Para charlar y escribir & Jogo de perguntas \\
\hline & \multirow{2}{*}{8} & Para oíry comprender & Depoimento \\
\hline & & Para charlar y escribir & Conversa sobre a casa \\
\hline
\end{tabular}

${ }^{9}$ Essa classificação dos gêneros se baseia nos enunciados das seções, pois não há uma preocupação do autor por explicitar o gênero a ser trabalhado. Isso está em consonância com o exposto por Cerutti-Rizzatti (2012), de que não há necessidade de categorização dos gêneros.

${ }^{10}$ Com base nos enunciados das atividades, optamos por usar diálogo para referir-nos ao texto escrito que aparece na seção Para oíry compreender, e conversa para referir-nos à interação proposta na seção Para charlary escribir.

${ }^{11} \mathrm{Na}$ unidade 6, a atividade consiste em fazer perguntas sobre características físicas para tentar adivinhar quem é a pessoa. Na unidade 7 , as perguntas são sobre a família de cada um. 
Como podemos perceber, na unidade 1 há pouca variedade dos gêneros orais trazidos tanto na parte de compreensão oral quanto na de produção oral. Como já havíamos salientado, a maioria das compreensões orais é de diálogos informais. Mas, no último capítulo, temos a presença de depoimento, em que pessoas falam sobre suas próprias casas, e percebemos uma relação com a produção oral, proposta ao final do capítulo, de que os alunos façam uma descrição do lugar onde vivem. Essa relação ocorreu, também, no segundo capítulo, em que o diálogo informal sobre trabalho pode, de certa forma, auxiliar na construção da entrevista de trabalho pedida na parte de produção oral. É importante observar, porém, que as entrevistas de trabalho se dão, normalmente, em contextos formais, portanto, se o diálogo trazido tivesse características e linguagem formais poderia contribuir mais para a prática da língua.

Nas atividades de produção oral da primeira unidade da coleção é recorrente a presença do gênero conversa informal, sem muitas instruções de como proceder e sempre relacionado ao tópico gramatical trazido no capítulo. Estruturas comunicativas de apoio também fazem parte da atividade proposta; por exemplo: na atividade para falar sobre o que gosta, aparece um quadro com frases e expressões com os verbos gostar e preferir (MARTIN, 2009, p. 84).

Aparentemente, a grande preocupação nas tarefas de produção oral era de fornecer as estruturas linguísticas a serem usadas nas conversas, mas, conforme Dolz, Noverraz e Schneuwly (2004), o conhecimento das características do gênero a ser produzido também pode contribuir para o êxito da comunicação.

$\mathrm{Na}$ segunda unidade da coleção, percebemos poucas mudanças com relação à variedade de gêneros orais, como podemos constatar no Quadro 2, a seguir. O diálogo informal continua sendo o gênero mais abordado e, muitas vezes, não contribui de maneira significativa com as atividades de produção oral. 
Quadro 2 - Variedade de gêneros orais presentes na unidade 2

\begin{tabular}{|c|c|c|c|}
\hline Unidade & Capítulo & Seções & Gênero oral \\
\hline \multirow{16}{*}{2} & \multirow{2}{*}{9} & Para oir y comprender & Diálogo informal \\
\hline & & Para charlar y escribir & Diálogo informal \\
\hline & \multirow{2}{*}{10} & Para oíry comprender & Entrevista \\
\hline & & Para charlar y escribir & Debate \\
\hline & \multirow{2}{*}{11} & Para oir y comprender & Diálogo informal \\
\hline & & Para charlar y escribir & Conversa formal \\
\hline & \multirow{2}{*}{12} & Para oir y comprender & Diálogo informal \\
\hline & & Para charlar y escribir & Diálogo informal \\
\hline & \multirow{2}{*}{13} & Para oir y comprender & Diálogo informal \\
\hline & & Para charlar y escribir & Jogo de perguntas \\
\hline & \multirow{2}{*}{14} & Para oíry comprender & Entrevista \\
\hline & & Para charlar y escribir & Conversa informal \\
\hline & \multirow{2}{*}{15} & Para oir y comprender & Diálogo informal \\
\hline & & Para charlar y escribir & Entrevista \\
\hline & \multirow{2}{*}{16} & Para oir y comprender & Programa jornalístico de rádio \\
\hline & & Para charlar y escribir & Jogo de perguntas \\
\hline
\end{tabular}

Conforme o Quadro 2, observamos que foram abordados novos gêneros como debate, entrevista e programa jornalístico de rádio. Nas propostas de produção oral da segunda unidade pudemos perceber que, em alguns casos, há a intenção de preparar o aluno um pouco melhor para a prática do gênero, como na proposta de um debate (MARTIN, 2009, p. 162) em que se faz uma breve exposição sobre o que são os argumentos 
para defender uma opinião e algumas frases e expressões para perguntar e emitir opinião. Nessa atividade, a instrução começa com uma explicação sobre a argumentação para depois propor o debate, mas não contribui no sentido de auxiliar o aluno com relação às outras características e regras do debate. Outra opção seria trazer algum texto de referência, como usaram Dolz, Noverraz e Schneuwly (2004), para que o aluno pudesse observar e inferir as características do gênero proposto. Vale ressaltar que em nenhuma das outras propostas da coleção há algo parecido. A preocupação com o tópico gramatical segue evidente, já que, antes de iniciar a atividade, o aluno recebe a indicação de que use, por exemplo, o pretérito imperfeito no jogo de perguntas, no capítulo 13 (MARTIN, 2009, p. 206) e o pretérito indefinido na entrevista, no capítulo 15 (MARTIN, 2009, p. 234).

Observamos ainda, no capítulo 11, que a proposta de produção oral é a prática de uma conversa formal entre um turista e funcionários de um hotel, estação de trem ou aeroporto, mas não existe uma problematização das implicações do uso do tratamento formal e os papéis dos interlocutores, por exemplo. Há somente amostras de frases a serem usadas na conversa.

Na unidade 3, o gênero oral diálogo informal continua predominante. A unidade traz alguns gêneros que não foram abordados anteriormente, mas não inovam no sentido de preparar melhor o aluno para a prática da oralidade. No Quadro 3, vemos os gêneros abordados.

Uma das dificuldades que encontramos nas análises dessa terceira unidade foi identificar o gênero a ser desenvolvido nas atividades de produção oral, porque, em geral, as tarefas são do tipo "Fale sobre..." e, em seguida, são expostas as estruturas linguísticas a serem utilizadas; por exemplo: na unidade 18, solicita-se a formulação de frases expressando desejos, dúvidas, etc.; na unidade 22 , solicita-se que o aluno fale sobre a influência de filmes violentos; e na unidade 19, propõe-se que o aluno opine sobre diferentes temas (com o objetivo de exercitar a capacidade argumentativa). 
Quadro 3 - Variedade de gêneros orais presentes na unidade 3

\begin{tabular}{|c|c|c|c|}
\hline Unidade & Capítulo & Seções & Gênero oral \\
\hline \multirow{16}{*}{3} & \multirow{2}{*}{17} & Para oíry comprender & Diálogo informal \\
\hline & & Para charlary escribir & Conversa informal \\
\hline & \multirow{2}{*}{18} & Para oíry comprender & Diálogo informal \\
\hline & & Para charlary escribir & Conversa $^{12}$ \\
\hline & \multirow{2}{*}{19} & Para oíry comprender & Diálogo informal \\
\hline & & Para charlary escribir & Argumentação/expressar opinião \\
\hline & \multirow{2}{*}{20} & Para oíry comprender & Leitura dramatizada \\
\hline & & Para charlary escribir & Receita \\
\hline & \multirow{2}{*}{21} & Para oir y comprender & Entrevista \\
\hline & & Para charlary escribir & Conversa informal \\
\hline & \multirow{2}{*}{22} & Para oíry comprender & Debate \\
\hline & & Para charlary escribir & Conversa informal \\
\hline & \multirow{2}{*}{23} & Para oíry comprender & Diálogo informal \\
\hline & & Para charlary escribir & Fofoca \\
\hline & \multirow{2}{*}{24} & Para oíry comprender & Diálogo informal \\
\hline & & Para charlary escribir & Conversa informal \\
\hline
\end{tabular}

Cabe mencionar que em nenhuma atividade de produção oral das três unidades há menção aos elementos paralinguísticos ou ao contexto sócio-

${ }^{12}$ Nessa atividade, é proposto que o aluno formule frases expressando dúvidas, desejos, possibilidades, conselhos, suposições, etc., mas não se explicita de que maneira (gênero) deve fazê-lo. 
histórico e cultural de produção do gênero discursivo oral. Esse fator é imprescindível, já que o que falar e, especialmente, o como falar diferem de uma cultura para outra (SOLER-ESPIAUBA, 2006; SARMENTO, 2004) Desconsiderar esses aspectos em propostas de produção oral em LE faz com que o aluno se expresse usando como parâmetro a sua LM (CESTERO MANCERA, 2012). Além disso, a não menção dos elementos não verbais relacionados com os gêneros é divergente de algumas estratégias que estão explicitadas no Manual do professor. Conforme o Manual (MARTIN, 2009, p. 2), a coleção se propõe a "apresentar grande variedade de textos, de gêneros diversos, para que o aluno aprenda a perceber e a utilizar o registro adequado às situações comunicativas" e defende que "a aprendizagem da língua estrangeira sirva de acesso ao conhecimento de culturas de outros grupos sociais".

Com relação à atividade intitulada Abora habla de ti, inserida na seção Para oíry compreender, notamos que sua composição é de perguntas relacionadas ao áudio inicial. Não há uma orientação sobre o procedimento a ser feito e não há inovação ao longo das mais de 400 páginas. Em todos os capítulos, a estrutura se repete, mas, no capítulo 11 do livro, ao propor que o aluno fale de viagens, o título da atividade é alterado para Ahora, oralmente, habla de ti. Ao colocar dessa forma, em apenas um capítulo, fica a dúvida se o falar proposto em outros capítulos era oral ou por escrito.

Em suma, as propostas de produção oral são, em sua maioria, interações verbais com os colegas ou emissão de opinião sobre determinado assunto, sem explicitar detalhadamente o gênero abordado ou apoiar-se em textos de referência, como mencionam Dolz, Noverraz e Schneuwly (2004). As propostas apresentadas remetem ao vocabulário estudado no capítulo ou à prática de algum tópico gramatical específico, não considerando aspectos importantes dos gêneros discursivos orais, tais como o contexto de produção, os participantes da interação, o entorno sócio-histórico, as ideologias implicadas e os elementos culturais subjacentes à prática interacional.

\section{Estrutura e Apresentação do Livro Didático Cercanía joven: espanhol: ensino médio}

O volume único selecionado para análise contém 367 páginas, mais o manual do professor, com 64 páginas. Está subdividido em nove unidades 
temáticas, com dois capítulos cada uma. Em cada capítulo se trabalham pelo menos duas das quatro habilidades linguísticas (leitura, audição, fala e escrita) em seções intituladas Escucha, Habla, Lectura e Escritura ${ }^{13}$.

$\mathrm{Na}$ seção intitulada Escucha, são propostas atividades de pré-audição (¿Qué voy a escuchar?), audição (Escuchando la diversidade de voces) e pós-audição (Comprendiendo la voz del otro), além de uma seção de percepção auditiva (Oído perspicaz: el español suena de maneras diferentes) ${ }^{14}$. O objetivo dessa seção é propor atividades que contemplem os textos orais tanto em seus aspectos sociais quanto em seus aspectos informativos. Assim, apresenta atividades de preencher lacunas, identificar palavras, reconhecer sentimentos através de tons de voz, identificar elementos extralinguísticos, como os ruídos do ambiente onde se desenvolve uma conversação, etc. Tais atividades são consoantes ao que prevê Cestero Mancera (2000), quanto ao papel do sistema não verbal na comunicação oral. De acordo com o Manual do professor, escutar

... envolve um amplo processo mental, tanto de compreensão do contexto imediato de produção da interação oral como de interpretação de todo o contexto sociocultural dessa interação. Os ouvintes devem não somente se mover por entre os diferentes sons, os significados das palavras e as estruturas gramaticais, mas também interpretar a entonação de voz, a ênfase expressiva, a intenção comunicativa. (COIMBRA; CHAVES; BARCIA, 2014, p. 7).

Na seção intitulada Habla são propostas atividades de expressão oral em três etapas: primeiro, em Lluvia de ideas ${ }^{15}$, se faz uma preparação dos estudantes para a interação oral, ativando seus conhecimentos ou apresentando informações sobre a situação comunicativa, tema e contexto de fala; em seguida, em Rueda viva: comunicándose $e^{16}$, os aprendizes interagem

\footnotetext{
${ }^{13}$ Escuta, Fala, Leitura e Escrita.

${ }^{14}$ O que vou escutar?, Escutando a diversidade de vozes, Compreendendo a voz do outro, Ouvido perspicaz: o espanhol soa de maneiras diferentes.

${ }^{15}$ Chuva de ideias.

${ }^{16}$ Roda-viva: comunicando-se.
} 
oralmente, conforme os propósitos comunicativos específicos; e, finalmente, em $\left\lceil A\right.$ concluir $!^{17}$, propõe-se uma reflexão sobre as interações orais desenvolvidas pelos aprendizes. Conforme o Manual do professor, considera-se:

Mais que falar a língua de forma fluente se espera desenvolver no aluno uma consciência conversacional, ampliando suas habilidades de: sentir-se a vontade e envolver-se positivamente na produção oral; saber pedir e ceder o turno de fala; aproveitar o tempo de que dispõe para falar; saber atender ao tema; negociar o significado e pontos de vista com o interlocutor; avaliar a compreensão do interlocutor e contribuir para a eficácia da interação oral. (COIMBRA; CHAVES; BARCIA, 2014, p. 9).

Na apresentação do livro, no Manual do professor, os autores afirmam que o livro está desenhado para alunos brasileiros do Ensino Médio e que se propõe a "ensinar a língua espanhola em contexto e em uso" (COIMBRA; CHAVES; BARCIA, 2014, p. 3). Ainda conforme os autores, o material

Propõe uma abordagem interativa, que valoriza os conhecimentos prévios e as vivências dos alunos para, ao mesmo tempo, inseri-los num novo panorama de conhecimentos socioculturais, artísticos e discursivos, convidando-os a perceber o mundo plurilinguístico e multicultural em que vivemos. (COIMBRA; CHAVES; BARCIA, 2014, p. 3).

Nesse sentido, o conhecimento linguístico da LM também deve ser considerado para o desenvolvimento das atividades propostas.

Seções específicas do livro didático Cercanía joven: espanhol: ensino médio

A análise do material foi feita considerando-se a divisão sugerida pelos autores de que, no primeiro ano sejam trabalhadas as três primeiras unidades;

${ }^{17}$ Vamos concluir! 
no segundo ano, as unidades intermediárias (4, 5 e 6), e no terceiro ano, que se trabalhem as três últimas unidades (7, 8 e 9). Essa é a divisão feita na edição do material, avaliada pelo PNLD 2015. Assim, observando-se o Quadro 4, a seguir, com relação ao espaço dado à oralidade no livro analisado, constata-se, que no primeiro ano, o gênero oral é trabalhado nas três unidades, sendo que se propõem atividades de escuta e fala nos capítulos 1, 2, 4 e 6. Nos capítulos 3 e 5, houve a combinação de atividades de leitura e escrita somente. O Quadro 4 explicita a variedade de gêneros orais trazida nas seções analisadas por unidades, para o primeiro ano:

Quadro 4 - Variedade de gêneros orais prevista para o primeiro ano

\begin{tabular}{|c|c|c|c|}
\hline Unidade & Capítulo & Seções & Gênero oral ${ }^{18}$ \\
\hline \multirow{2}{*}{1} & 1 & Escucha & Letra de Canción sobre el mundo latino \\
\cline { 2 - 5 } & 2 & Habla & Entrevista en la aduana \\
\hline \multirow{2}{*}{2} & 4 & Escucha & Entrevista televisiva a un astro del fútbol \\
\cline { 2 - 4 } & 4 & Habla & Invitación \\
\hline \multirow{3}{*}{3} & 6 & Escucha & $\begin{array}{r}\text { Invitación y noticia sobre las desapariciones en } \\
\text { la dictadura argentina }\end{array}$ \\
\cline { 2 - 4 } & 6 & Habla & Debate sobre el voto obligatorio \\
\hline
\end{tabular}

Observe-se que há certa variedade de gêneros orais (canção, entrevista, convite e debate). No que se refere, principalmente, à expressão oral (entrevista, convite e debate), considera-se que as propostas são bastante arrojadas, posto que, para muitos alunos, essa pode ser a sua primeira experiência de aprendizagem da língua espanhola. Em vista disso, questiona-se, por exemplo, quais seriam as condições linguísticas para que o aluno do primeiro ano do ensino médio possa participar satisfatoriamente de um debate, como o que é proposto na unidade 3, no capítulo 6

${ }^{18}$ Seguimos a classificação dos gêneros que está explicitada nas unidades e no sumário da coleção. 
(COIMBRA; CHAVES; BARCIA, 2014, p. 98-103). Nas atividades preparatórias a essa interação oral, propõe-se uma breve compreensão textual sobre o que é um analfabeto político, de Bertold Brecht; em seguida, apresenta-se um infográfico com o que é necessário para votar conscientemente, em que os alunos devem opinar; posteriormente, apresentase uma lista de argumentos favoráveis ou não à obrigatoriedade do voto para que os alunos se posicionem a respeito; por último, apresenta-se uma tabela com fatores que mais causam problemas sociais no Brasil, para trabalhar com estruturas comparativas. A partir disso, a atividade de expressão oral é proposta, sem que seja feita qualquer menção sobre marcadores argumentativos, por exemplo, os quais são muito comuns nesse gênero. Merece destaque, porém, que junto à instrução da atividade há uma explicação sobre algumas características de um debate (COIMBRA; CHAVES; BARCIA, 2014, p. 102).

Por outro lado, dentre as atividades propostas, deve-se ressaltar as atividades de compreensão oral que exploram diversas características dos gêneros, e em todas se propõem momentos de reflexão sobre o sistema linguístico, a serviço do propósito comunicativo do gênero. Em todas as seções, por exemplo, são propostas atividades de percepção fonéticofonológica, em alguns casos apresentando aspectos de variedades linguísticas, como as pronúncias das letras $<\mathrm{ll}>\mathrm{e}\langle\mathrm{y}\rangle$, por exemplo, envolvidas no fenômeno conhecido como yeísmo, e das letras $\left.<_{\mathrm{s}}>,{ }_{\mathrm{z}}\right\rangle_{\mathrm{e}}<\mathrm{c}>$, que envolvem os fenômenos de seseo, сесеo e pronúncia interdental.

$\mathrm{Na}$ parte do material dedicada ao segundo ano do Ensino Médio, observa-se que o gênero oral é trabalhado nas três unidades, sendo que são propostas atividades orais nos capítulos 7, 8, 10 e 12. Nos capítulos 9 e 11, houve a combinação de atividades de leitura e escrita somente. O Quadro 5 explicita a variedade de gêneros orais trazida nas seções analisadas por unidades, para o segundo ano: 
Quadro 5 - Variedade de gêneros orais prevista para o segundo ano

\begin{tabular}{|c|c|c|c|}
\hline Unidade & Capítulo & Seções & Gênero oral \\
\hline \multirow{2}{*}{4} & 7 & Habla & Presentación \\
\cline { 2 - 5 } & 8 & Escucha & Entrevista sobre la poesía escrita en lengua bubi \\
\hline \multirow{3}{*}{5} & 10 & Escucha & $\begin{array}{c}\text { Letra de canción "Antes muerta que sencilla", de } \\
\text { Maria Isabel }\end{array}$ \\
\cline { 2 - 4 } & 10 & Habla & Diálogo de compra y venta \\
\hline \multirow{3}{*}{6} & 12 & Escucha & $\begin{array}{c}\text { Reportaje sobre el futuro de las tienditas frente a los } \\
\text { supermercados }\end{array}$ \\
\cline { 2 - 4 } & 12 & Habla & Encuesta mercadillos $x$ supermercados \\
\hline
\end{tabular}

Observa-se que as atividades abrangem diferentes gêneros orais (apresentação, entrevista, canção, diálogo, reportagem e questionário), sendo que a interação oral é proposta a partir de atividades de apresentação, diálogo e questionário. Nesse caso, pode-se verificar que as atividades de compreensão oral exploram diferentes características dos gêneros, além do que se refere ao sistema linguístico, como no caso da entrevista (COIMBRA; CHAVES; BARCIA, 2014, p. 137), em que se pede que os alunos identifiquem os ruídos de fundo, presentes na gravação, e no caso da reportagem sobre o futuro das tendas e supermercados, em que se chama a atenção para as funções e usos de marcadores conversacionais (COIMBRA; CHAVES; BARCIA, 2014, p. 197). Deve-se ressaltar o tratamento dado aos elementos extralinguísticos (ruídos) e linguísticos (marcadores conversacionais) típicos da comunicação oral.

A proposta de expressão oral denominada de apresentação, porém, precisa ser problematizada. $\mathrm{Na}$ verdade, cria-se um contexto em que os alunos devem simular serem tradutores simultâneos em um evento em que irão apresentar algum ponto turístico do Rio de Janeiro. Nesse caso, considera-se que há uma falha no que se refere ao aspecto da autenticidade da produção, porque ser tradutor nesse contexto não é muito usual para alunos do segundo ano do ensino médio. Além disso, ter que desempenhar esse papel para falar de um ponto turístico que pode ser desconhecido pelo 
aluno torna essa atividade bastante complexa e superficial. Sendo assim, a perspectiva de trabalho a partir de um gênero oral não se cumpre de forma satisfatória.

$\mathrm{Na}$ parte do material dedicada ao terceiro ano do Ensino Médio, observa-se que o gênero oral também é trabalhado nas três unidades, sendo que se propõem atividades orais nos capítulos 13, 14, 15 e 18. Nos capítulos 16 e 17, houve a combinação de atividades de leitura e escrita somente. O Quadro 6 explicita a variedade de gêneros orais trazida nas seções analisadas por unidades, para o terceiro ano do Ensino Médio:

Quadro 6 - Variedade de gêneros orais prevista para o terceiro ano

\begin{tabular}{|c|c|c|c|}
\hline Unidade & Capítulo & Seções & Gênero oral \\
\hline 7 & 13 & Escucha & $\begin{array}{c}\text { Spot de campaña sobre el medioambiente y la } \\
\text { sostenibilidad }\end{array}$ \\
\cline { 2 - 5 } & 14 & Habla & Llamada telefónica a un amigo \\
\hline 8 & 15 & Escucha & Charla de orientación vocacional \\
\cline { 2 - 5 } & 15 & Habla & Invitación de trabajo voluntario \\
\hline \multirow{2}{*}{9} & 18 & Escucha & $\begin{array}{c}\text { Charla entre padre de alumno, directora y profesora } \\
\text { de un colegio sobre Educación Sexual }\end{array}$ \\
\cline { 2 - 4 } & 18 & Habla & $\begin{array}{c}\text { Presentación oraly relato sobre cambios físicos y en el } \\
\text { estado de ánimo. }\end{array}$ \\
\hline
\end{tabular}

A proposta de trabalho abrange diferentes gêneros orais $\left(s p o t^{19}\right.$, chamada telefônica, conversa, convite e apresentação), sendo que a interação oral é proposta a partir de chamada telefônica, convite e apresentação. Novamente podeM-se observar atividades de compreensão oral que buscam propiciar a reflexão linguística desde o nível fonético-fonológico, como a percepção dos sons de <v> e <b> (COIMBRA; CHAVES; BARCIA, 2014,

19 Spoté um tipo de publicidade estruturada a partir do uso de diferentes recursos radiofônicos para a transmissão da mensagem. Distingue-se do jingle, pois este, por exemplo, usa a música somente como forma de facilitar a memorização. 
p. 218), de consoantes nasais (COIMBRA; CHAVES; BARCIA, 2014, p. 247) e do <x> (COIMBRA; CHAVES; BARCIA, 2014, p. 297), até o nível suprassegmental e extralinguístico, como na atividade de identificação do grau de seriedade de uma conversa e de tons de fala irônicos (COIMBRA; CHAVES; BARCIA, 2014, p. 213) e a de identificação de emoções na voz de diferentes interlocutores (COIMBRA; CHAVES; BARCIA, 2014, p. 290).

Nas atividades de expressão oral baseadas em gêneros orais mais conhecidos pelos alunos, observa-se uma preocupação por explicitar tipos de estruturas linguísticas que devem aparecer nas produções, como o presente do subjuntivo para fazer um convite a um trabalho voluntário (COIMBRA; CHAVES; BARCIA, 2014, p. 250) e verbos de cambio para fazer uma apresentação pessoal (COIMBRA; CHAVES; BARCIA, 2014, p. 300). Isso pode prejudicar a naturalidade da comunicação; além disso, é possível cumprir o objetivo comunicativo de cada proposta sem necessariamente usar tais estruturas.

Um aspecto que chama a atenção na obra como um todo é que as atividades de expressão oral eram, na grande maioria das vezes, precedidas de atividades prévias a partir de um texto escrito e de exercícios de recuperação lexical e gramatical, que poderiam ser úteis na interação oral. Mas, em muitos casos, isso não parece ter sido suficiente para a realização da atividade oral, e, junto à instrução sobre a interação, havia uma lista de expressões úteis na conversação. Um exemplo disso está na atividade que propunha um diálogo de compra e venda. $\mathrm{Na}$ atividade prévia (Lluvia de ideas), propôs-se a compreensão textual de um artigo intitulado Esplendor y decadencia, el ciclo de la vida; em seguida havia uma exercício de vocabulário sobre vestimentas e, por último, um exercício sobre frases e expressões usadas em diálogos de compra e venda. Mas a atividade de produção oral em si solicitava que os alunos atuassem como vendedores e compradores num mercado ecológico. Nesse caso, é possível que os alunos não saibam como iniciar uma conversação, como tomar, ceder e intercambiar os turnos de fala, pois não tiveram uma amostra do gênero (via audição ou vídeo) em que se basear. Em outras palavras, ressalta-se que o uso de gêneros orais também como insumo linguístico nas atividades prévias pode potencializar o conhecimento e desempenho dos aprendizes em diferentes gêneros orais, pois permite chamar a atenção, para os aspectos extralinguísticos e 
paralinguísticos que contribuem para a construção e negociação de sentidos, além das formas linguísticas (léxico e gramática).

\section{Considerações Finais}

Este estudo visava a analisar a abordagem dos gêneros discursivos orais em duas coleções de espanhol para o ensino médio. As análises mostram que houve evolução na abordagem da oralidade, considerando-se a perspectiva de trabalho a partir de gêneros orais, ao comparar-se o livro Sintesis com o livro Cercanía Joven. Em ambos os livros predominam as atividades que privilegiam os gêneros discursivos escritos, mas o segundo livro apresenta uma variedade maior de gêneros orais, seja em atividades de compreensão, seja em atividades de interação oral.

$\mathrm{Na}$ primeira coleção, observamos que, em praticamente todos os capítulos, a atividade que se segue à de produção oral é uma produção escrita sobre o que foi exposto oralmente, tornando o gênero oral um pretexto para a produção escrita. Sob esse aspecto, percebemos que, muitas vezes, um gênero que seria essencialmente oral estabelece uma relação de interdependência com o escrito que poderia ser desconsiderada. Ao estabelecer relações que não são necessárias ou usar uma proposta, como pretexto da outra, perde-se um pouco o caráter do gênero em si.

Por outro lado, a segunda coleção apresenta atividades prévias à proposta de expressão oral relacionadas com gêneros escritos, deixando de aproveitar as vantagens do insumo linguístico e contextual que a audição de gêneros orais poderia trazer para a produção oral. Parece haver um pressuposto de que o aluno já domina o gênero oral abordado, sendo necessária somente a ativação de conhecimentos lexicais e gramaticais como preparação para o seu desenvolvimento. A esse respeito, Dolz, Schneuwly e Haller (2004), ao considerarem que os gêneros orais devem ser trabalhados e desenvolvidos, propuseram sequências didáticas para que gêneros orais mais complexos estivessem presentes em sala de aula. Nesse sentido, o contato prévio com uma amostra oral de um gênero a ser produzido pode ser muito benéfico para o aprendiz.

Cabe ressaltar que sem uma preparação mais precisa sobre o gênero oral a ser produzido, incluindo aqui o contato prévio com amostras desse 
gênero, o aluno pode se basear em conhecimentos de sua LM para se expressar em LE. Entretanto, nem sempre os gêneros se constituem da mesma maneira em línguas diferentes; assim, nessa transposição de gêneros de uma língua para outra, equívocos sociais, históricos, ideológicos e culturais podem ocorrer, já que elementos pragmáticos e culturais intrínsecos a cada sistema linguístico são desconsiderados.

Embora nosso trabalho não esgote os aspectos de análise da oralidade nos LDs, esperamos que possa contribuir, de alguma maneira, para os estudos da oralidade em LE, e auxiliar professores de língua espanhola a analisar criticamente as atividades de compreensão e produções orais disponíveis, no intuito de poder complementá-las, considerando os aspectos intrínsecos e extrínsecos da fala, para que o gênero oral possa ser contemplado de maneira cada vez mais efetiva e significativa nas aulas.

\section{Referências}

AQUINO, C. de. Questões sobre o trabalho com gêneros textuais na sala de aula de língua estrangeira: uma discussão sob a ótica bakhtiniana. BELT Journal, Porto Alegre, v. 2, n. 2, p. 154-166, 2011.

BAKHTIN, M. Os gêneros do discurso. In: BAKHTIN, M. Estética da criação verbal. 4. ed. Tradução Paulo Bezerra. São Paulo: Martins Fontes, 2003. p. 261-306.

BEZERRA, M. A.; REINALDO, M. A. Análise linguística na sala de aula. In: BEZERRA, M. A.; REINALDO, M. A. Análise linguística: afinal, a que se refere? São Paulo: Cortez, 2013.

BRAIT, B.; PISTORI, M. H. C. A produtividade do conceito de gênero em Bakhtin e o Círculo. Alfa, São José do Rio Preto, v. 56, n. 2, p. 361-718, 2012.

BRASIL. Guia de livros didáticos: PNLD. 2012: Língua Estrangeira Moderna. Brasília: Ministério da Educação; Secretaria de Educação Básica, 2011. 
BRASIL. Guia de livros didáticos: PNLD. 2015: Língua Estrangeira Moderna. Brasília: Ministério da Educação; Secretaria de Educação Básica, 2014.

CESTERO MANCERA, A. M. Comunicación no verbal y desarrollo de la expresión oral en la enseñanza y el aprendizaje de lenguas extranjeras. Carabela, Madrid, n. 47, p. 69-86, 2000.

CESTERO MANCERA, A. M. La enseñanza de la conversación en ELE: estado de la cuestión y perspectivas de futuro. Revista Internacional de Lenguas Extranjeras, Tarragona, n. 1, p. 31-62, 2012.

CERUTTI-RIZZATTI, M. E. Ensino de língua portuguesa e inquietações teórico-metodológicas: os gêneros discursivos na aula de português e a aula (de português) como gênero discursivo. Alfa, São José do Rio Preto, v. 56, n. 1, p. 249-269, 2012.

COIMBRA, L.; CHAVES, L. S.; BARCIA, P. L. Cercania joven: espanhol ensino médio. São Paulo: Edições SM, 2014.

DOLZ, J.; SCHNEUWLY, B.; HALLER, S. O oral como texto: como construir um objeto de ensino. In: DOLZ, J.; SCHNEUWLY, B. Gêneros orais e escritos na escola. Campinas: Mercado de Letras, 2004. p. 125-155.

DOLZ, J.; NOVERRAZ, M.; SCHNEUWLY, B. Seqüências didáticas para o oral e a escrita: apresentação de um procedimento. In: DOLZ, J.; SCHNEUWLY, B. Gêneros orais e escritos na escola. Campinas: Mercado de Letras, 2004. p. 81-108.

LOPES-ROSSI, M. A. G. A produção escrita de gêneros discursivos em sala de aula: aspectos teóricos e sequência didática. Signum: Estudos da Linguagem, Londrina, v. 15, n. 3 (esp), p. 223-245, dez. 2012.

MARCUSCHI, L. A. Concepção de língua falada nos manuais de português de $1^{\circ}$ e $2^{\circ}$ graus: uma visão crítica. Trabalhos em Lingüistica Aplicada, Campinas, v. 30, p. 39-79, jul./dez. 1997.

MARCUSCHI, L. A. Gêneros textuais: definição e funcionalidade. In: DIONÍSIO, A. P.; MACHADO, A. R.; BEZERRA, M. A. (Orgs.). Gêneros textuais \& ensino. Rio de Janeiro: Lucerna, 2002. p. 19-36. 
MARTIN, I. Sintesis: curso de lengua española. São Paulo: Ática, 2009.

ROJO, R.; SCHNEWLY, B. As relações oral/escrita nos gêneros orais formais e públicos: o caso da conferência acadêmica. In: BONINI, A.; FURLANETTO, M. M. (Orgs.). Linguagem em Discurso: gêneros textuais e ensino-aprendizagem. Tubarão: Unisul, 2006.

ROSA, A. A. C. Gêneros orais na escola pública: o gênero debate na formação crítica do sujeito. EntreLetras, Araguaína, n. 1., p. 151-165, 2010.

SACKS, H.; SCHEGLOFF, E.; JEFFERSON, G. Sistemática elementar para a organização da tomada de turnos para a conversa. Tradução Adriana Maria Soares da Cunha et al. Veredas, Juiz de Fora, v. 7, n. 1-2, p. 9-73, 2003.

SARMENTO, S. Ensino de cultura na aula de língua estrangeira. ReVEL, v. 2, n. 2, p. 1-22, mar. 2004. Disponível em: <http://bit.do/bFaoT>. Acesso em: 25 out. 2014.

SILVA, C. R.; ANDRADE, D. N. P.; OSTERMANN, A. C. Análise da Conversa: uma breve introdução. ReVEL, v. 7, n. 13, p. 1-21, ago. 2009. Disponível em: <http://bit.do/bFapb>. Acesso em: 25 out. 2014.

SWIDERSKI, R. M. da S.; COSTA-HÜBES, T. C. Um estudo sobre proposta de trabalho com gêneros discursivos orais na formação de professores. In: SEMINÁRIO INTERNACIONAL DE ESTUDOS DOS GÊNEROS TEXTUAIS - SIGET, 6., 2011, Natal. Anais... Natal: UFRN, 2011. v. 1. p. 1-19.

SOLER-ESPIAUBA, D. Contenidos culturales en la enseñanza del español como 2/L. Madrid: Arco; Libros, 2006.

VÁZQUEZ, G. La destreza oral: conversar, exponer, argumentar. Madrid: Edelsa, 2000.

Recebido em: 26/05/2015

Aceito: 19/11/2015 